\title{
Comparison of clinical characteristics and outcomes of bloodstream infections due to multidrug-resistant Acinetobacter baumannii and other Gram-negative bacteria in ICU patients
}

\section{Ying Qian}

Lianyungang No 1 People's Hospital

\section{Yongpeng Xie}

Lianyungang No 1 People's Hospital

\section{Haifeng Mao}

Lianyungang No 1 People's Hospital

Jiguang Li

Lianyungang No 1 People's Hospital

Caihong Gu

Lianyungang No 1 People's Hospital

Suxia Liu

Lianyungang No 1 People's Hospital

Kexi Liu ( $\sim$ liukexi2006@163.com )

Lianyungang No 1 People's Hospital

Research article

Keywords: Acinetobacter baumannii, Multidrug-resistant bloodstream infection, Gram-negative bacteria, Intensive care unit

Posted Date: January 14th, 2020

DOI: https://doi.org/10.21203/rs.2.20802/v1

License: (a) (i) This work is licensed under a Creative Commons Attribution 4.0 International License.

Read Full License 


\section{Abstract}

Background: Multidrug-resistant (MDR) bloodstream infection (BSI) by Gram-negative bacteria (GNB) is an important cause of mortality in the intensive care unit (ICU). The purpose of this study was to compare the clinical characteristics of some GNB BSIs and to analyze their drug resistance, with an emphasis on the analysis of prognostic risk factors related to MDR-Acinetobacter baumannii (A. baumannii) BSI.

Methods: A retrospective study was conducted in the ICU of lianyungang hospital in China. Patients with BSIs due to MDR-A. baumannii, MDR-Klebsiella pneumoniae (K. pneumoniae), MDR-Pseudomonas aeruginosa (P. aeruginosa) and MDR-Escherichia coli (E. coli) were included.

Results: The overall drug resistance rate to imipenem of A. baumannii and K. pneumoniae was significantly higher than that of P. aeruginosa and E. coli $(95.8 \%$ and $75.5 \%$ vs $44.6 \%$ and $9.2 \%$ respectively). The mortality rates were $71.9 \%, 63.3 \%, 41.5 \%$ and $38.1 \%$, respectively. The multivariate analysis of MDR-A. baumannii BSI, APACHE II score, hormone use, development of septic shock were associated with the 30-day mortality, while high albumin level with survival.

Conclusion: The treatment of MDR-A. baumannii and MDR-K. pneumoniae infection resulted difficult due to their high drug resistance rate. However, the understanding of the clinical characteristics of different BSIs might be helpful to predict, to some extent, the pathogenic bacteria involved so as to proceed with an early sensitive antibiotic treatment. The high mortality rate due to BSI MDR-A. baumannii might be correlated with APACHE II score, nutritional status, and hormone therapy, while septic shock was a warning sign of poor prognosis.

\section{Background}

Gram-negative bacteria (GNB) are very common pathogenic bacteria in the ICU [1-3]. Since the drug resistance rate continues to increase, it often causes refractory infections, among which the most serious is the bloodstream infection (BSI). Data from the China Antimicrobial Surveillance Network (CHINET) in 2018 (http://chinets.com/) show that the top four GNB causing BSIs are Escherichia coli (E. coli) (23.05\%), Klebsiella pneumoniae (K. pneumoniae) (15.45\%), Acinetobacter baumannii (A. baumannii) (3.2\%) and Pseudomonas aeruginosa (P. aeruginosa) (2.9\%). BSIs from these bacteria often occur in severe patients due to a frequent exposure to broad-spectrum antibiotics, weak immunity, facility to be colonized, and who often receive invasive procedures [4-7].

Many studies are available comparing the clinical characteristics of BSIs due to the same bacterium type with the resistance to different drugs, but few studies compare BSIs caused by different GNB. Each bacterium has its own pathogenic characteristics, mainly resulting in different vulnerable population and mortality. Recent studies found that the multi-drug resistance (MDR)-A. baumannii BSI has an alarming death rate, exceeding 70\% in the ICU [8-10]. However, the reported mortality of BSIs in the ICU caused by K. pneumoniae [8], E. coli [11, 12] and P. aeruginosa [13] was approximately $40 \%$. According to the current 
situation, the aim of this study was to analyze the clinical characteristics of MDR-A. baumannii BSI and other GNB BSIs, and the prognostic factors of MDR-A. baumannii BSI.

\section{Methods}

\section{Study design and patient selection}

This was a retrospective observational study conducted at the Affiliated Lianyungang Hospital of Xuzhou Medical University with 2500 beds in China. ICU patients with BSIs due to MDR- $A$. baumannii, MDR-K. pneumoniae, MDR-P. aeruginosa and MDR-E. coli from Feb 2013 to Sep 2019 were included and analysed in this study, respectively including $96,147,65,76$ bacteremic episodes. The inclusion criteria were the following: (1) age $\geq 18$ years; (2) blood culture positive for MDR-A. baumannii, MDR-K. pneumoniae, MDR$P$. aeruginosa, MDR-E. coli; (3) clinical symptoms consistent with infection. Multiple positive cultures associated to the same patient were considered as one episode. Our study was conducted according to the principles stated in the Declaration of Helsinki and has been approved by local Ethical Committees (YJ-20190625001).

\section{Clinical data collection}

Pre-designed questionnaires were used to collect patient data from the Electronics Medical Records management system or clinical charts. The following information was reviewed: demographics; microbial drug resistance; comorbidities; cause of ICU admission; source of infection; microorganism colonization or infection prior to BSIs; Length of ICU stay within 30 days before infection; length of hospitalization before infection; albumin level before infection; previous chemotherapy or radiotherapy; antibiotics received before infection; transfusion before infection; previous steroid treatment; neutropenia before infection; parenteral nutrition before infection; acute physiological and chronic health assessment (APACHE II) score; all-cause 28-day mortality. As regard MDR-A. baumannii BSI, the immune response after infection by leukocyte and neutrophil changes was also evaluated, and the function of the organ or system after infection. Infections were not treated with colistin because it was not available in our hospital.

\section{Definitions}

The infection caused by MDR-A. baumannii or other GNB was defined as clinical signs of the systemic inflammatory response syndrome and positive culture. Infection onset was defined as the date of collection of the first positive blood culture for the observed pathogen. Primary bacteraemia was recorded if no source was identified. Before the infection onset, isolation of any microorganisms in other sites such as urine, lung, abdomen and skin were recorded as microorganism colonization or infection. Neutropenia was defined as an absolute neutrophil count < 1500/ $\mu$ l. Weak leukocyte response was defined as leucocyte lower than the pre-infection level by multiple tests within 2 days after the infection onset. Neutrophil deficiency was defined as an absolute neutrophil count $<500 / \mu \mathrm{l}$. Prior antibiotic therapy was defined as the use of antibiotics for $>48 \mathrm{~h}$ within the 30 days before the infection onset. Steroid treatment was defined as an administration > $20 \mathrm{mg} /$ day of prednisone (or its equivalent) for 3 or more days. 
Sensitive antibiotic therapy was defined as the therapy with at least one agent which has in vitro activity against the infecting pathogen. Length of ICU and hospitalization stay were expressed by the number of days from the date of admission to the date of the infection onset. Septic shock was defined according to the international consensus definition [14]. MDR was defined as the resistance to at least one agent in three or more categories of antibiotics [15].

\section{Bacterial isolation and identification}

Isolated bacteria were identified by the Vitek 2 system (bioMérieux, Marcy l'Etoile, France). According to the Clinical and Laboratory Standards Institute, the drug susceptibility test was performed by disk diffusion method or dilution method. Extended spectrum beta-lactamases (ESBLs) production was tested by disk diffusion method. Colistin resistance test was not routinely carried out in our hospital, but the strains included in our study were all sensitive to colistin when the susceptibility test was performed.

\section{Statistical analysis}

Statistical analysis was performed using SPSS version 23.0. Continuous variables were presented as mean \pm standard deviation (by Student's $t$-test) or as the median (the upper quartile, the lower quartile) (by Kruskal Wallis rank-sum test) when the distribution was not normal. Categorical variables were described by frequency (percentage), using the Chi-square test or Fisher exact test. Cox risk proportion model was used, variables with statistical significance in the univariate analysis were included in the multivariate model, and stepwise forward regression was used to screen variables; the entry criterion was 0.05 , and the exclusion criterion was 0.10 . Time to mortality was analysed using the Kaplan-Meier survival curve and the log-rank test by Graphpad Prism 6.0. $P<0.05$ was considered statistically significant, and all the tests were 2-tailed.

\section{Results}

\section{BSI characteristics by different GNB}

Patient characteristics are summarized in Table 1. Twenty-seven (35.5\%) cases of MDR-E. coli BSI were considered as community-acquired BSIs (which occurred before or within 48 hours after admission), all the rest were hospital-acquired BSIs.

The average age of patients with MDR-P. aeruginosa and MDR-E. coli BSIs was approximately 5 years younger than that of the other two groups $(P=0.002)$. In patients with MDR- $A$. baumannii and MDR- $K$. pneumoniae BSIs, the prevalence rate of underlying diseases was high, especially chronic lung disease $(P=0.003)$ and chronic kidney disease $(P<0.001)$. In addition to MDR-E. coli BSI group, approximately half or more than half patients in other groups were admitted to ICU due to severe pneumonia and respiratory failure (both $P<0.001$ ). The proportion of patients with MDR-E. coli BSI admitted to ICU due to urinary tract infection, abdominal infection, shock, renal failure, and post-operation complications were higher than the 
proportion of other BSIs (shock $P=0.009$, other $P<0.001$ ). Admission to ICU due to burns was more commonly characterized by MDR-P. aeruginosa BSI $(P<0.001)$ compared to other BSIs.

Central venous catheter (CVC) $(P=0.037)$ and pneumonia $(P<0.001)$ as the source of infection were more commonly characterized by MDR-A. baumannii and MDR-K. pneumoniae BSIs, while intra-abdominal and urinary tract infections (all $P<0.001$ ) were more commonly characterized by MDR-E. coli BSIs compared with other BSIs. Patients with MDR-P. aeruginosa BSIs showed a higher frequency of skin and soft tissue infections $(P=0.001)$ than those with other BSIs. The MDR-E. coli BSI was the one less characterized by a previous infection or colonization by any microorganisms, while the MDR-A. baumannii BSI was the one mostly characterized by a previous fungal infection or colonization $(P=0.008)$. CVC, invasive mechanical ventilation, tracheotomy, nasogastric tube or nasointestinal tube, and urinary tube were often characterized by MDR-A. baumannii BSI, but rarely characterized by MDR-E. coli BSI compared with other BSIs (tracheotomy, $P=0.003$, other, $P<0.001$ ). Before the infection onset, the length of ICU stay and hospitalization (all $P<0.001$ ) were the longest in the MDR-A. baumannii BSI group, and the shortest in the MDR-E. coli BSI group. A significant difference in albumin content was observed before the infection onset $(P<0.001)$. Treatment with 3 or more classes of antibiotics was more common in the MDR-A. baumannii group and MDR-K. pneumoniae BSI group $(P<0.001)$. Mortality was significantly different among the groups $(P<0.001)$, with MDR-A. baumannii having the highest mortality.

\section{Analysis of the antibiotic resistance rate}

Antibiotic resistance is shown in table 2. In the MDR-K. pneumoniae group, 41 (27.9\%) were infected with ESBLs-producing strains, while in the MDR-E. coli group, 56 (73.7\%) were infected with ESBLs-producing strains. The resistance rates of MDR-A. baumannii, MDR-K. pneumoniae, MDR-P. aeruginosa and MDR-E. coli to imipenem were $95.8 \%, 75.5 \%, 44.6 \%$ and $9.2 \%$, respectively. MDR-A. baumannii had relatively low resistance to amikacin and sulfamethoxazole trimethoprim ( $53.1 \%$ and $64.6 \%$, respectively). Ad regard MDR-K. pneumoniae, the resistance to tigecycline was the lowest (31.3\%). The resistance rate of MDR-P. aeruginosa to piperacillin tazobactam, amikacin, ceftazidime and levofloxacin ranged from 23 to $31 \%$. Overall, MDR-E. coli had the lowest drug resistance rate, but the resistance rate for levofloxacin was relatively high (71.9\%).

\section{Risk factors related to the mortality of MDR-A. baumannii BSI}

COX regression analysis of risk factors related to the outcome of MDR-A. baumannii BSI is shown in table 3. APACHE II score (HR 1.13, CI 95\% 1.04-1.23, $P=0.005$ ), previous steroid treatment (HR 2.18, Cl 95\% 1.24$3.84, P=0.007$ ) and deterioration of the circulatory system (septic shock) after infection (HR 2.14, $\mathrm{Cl} 95 \%$ 1.18-3.89, $P=0.013$ ) were associated with increased 28-day mortality, while high albumin level (HR 0.918, $\mathrm{Cl} 95 \%$ 0.86-0.98, $P=0.01$ ) was related to higher 28 -day survival.

Finally, the Kaplan-Meier analysis of the 28-day survival of patients in each BSI group is reported in Fig. 1. As regard MDR-A. baumannii BSIs, the Kaplan-Meier analysis of 28-day survival of patients associated with a previous steroid treatment and septic shock was also reported. 


\section{Discussion}

This study demonstrated that BSI caused by different GNB had significantly different clinical characteristics by comparing the risk factors such as causes of ICU admission, underlying diseases, sources of infection, treatment and invasive procedures.

\section{MDR-K. pneumoniae BSIs}

A meta study [16] found that the main risk factors for carbapenem-resistant $K$. pneumoniae (CR $K$. pneumoniae) infection included: long hospital stay or ICU stay, previous use of carbapenems and steroids, CVC implantation, mechanical ventilation and tracheostomy, with the first three as the major risk factors. Our study found that all the above risk factors included a higher proportion of $K$. pneumoniae infections (mainly CR K. pneumoniae), but a less proportion of $A$. baumannii infection, compared with $P$. aeruginosa and $E$. coli infection. Other studies $[8,17,18]$ have confirmed some of the above risk factors, and found that CR K. pneumoniae colonization is a strong risk factor for later infection. In our study, K. pneumoniae was found in $64.6 \%$ of patient specimens before the infection onset, and most of them were colonized bacteria. K. pneumoniae can asymptomatically colonize the skin, mouth, respiratory tract and intestines, and intestinal colonization is closely related to subsequent infections [19-21]. Thus, we suspected that $K$. pneumoniae in this study might mainly come from the direct or indirect gut microbiota. One study found that the intestinal decontamination can decrease the incidence rate of ICU-acquired GNB BSI by $45 \%$, while the selective oropharyngeal decontamination only decreased by $33 \%$ [22]. However, in a randomized trial of 8665 patients [23], oropharyngeal decontamination or SDD did not reduce mortality in ICU-acquired MDR-GNB BSI compared with the standard care. The all-cause mortality in our study was $63.3 \%$, thus higher than 44.5\% [8] (mortality due to CR K. pneumoniae BSI in ICU patients). Another study [24] found that mortality rates varied with severity, since in high-risk patients the mortality rate of CR $K$. pneumoniae BSI is $77 \%$, while it is $45 \%$ in middle-risk patients. Therefore, we hypothesized that the mortality was closely related to the general condition and treatment strategy.

\section{MDR-E. coli BSIs}

Although $E$. coli is present in the normal intestinal flora, it can enter and survive in a sterile parenteral environment, which often leads to urinary tract infections and BSI [25]. Indeed, E. coli is the most important pathogenic bacteria in urinary and abdominal infections [26] and BSI. One study reported that $76 \%$ of $E$. coli BSIs come from home, and the most common source of home-acquired $E$. coli BSIs was the urinary tract, while the gastrointestinal tract was the common source for nosocomial E. coli BSIs [27]. Our observations were similar with the above observations. Patients in the $E$. coligroup were admitted to the ICU mainly for septic shock or renal failure secondary to urinary or abdominal infection, and BSI often occurred within 48 hours after the transfer from the general ward or community to the ICU, thus, the previous duration of hospital stay and ICU stay were short. In this study, most MDR-E. coli were ESBLsproducing strains and Ajao et al. [28] found that colonization and exposure to multiple antibiotics are independent risk factors for infection with E. coli-producing ESBLs. However, these factors were not significantly present in our study due to short hospital stay and unclear out-of-hospital medication for 
some patients. Overall, the E. coli group was significantly different from the other groups due to its special source of infection, and the mortality rate was low thanks to the ease of keeping its infections under control and easy access to sensitive antibiotics.

\section{MDR-P. aeruginosa BSIs}

Unlike other bacteria, $P$. aeruginosa not only has high virulence, but also has inherent resistance to some antibiotics and is prone to drug resistance. Our study found that $P$. aeruginosa BSIs were common in immunocompromised patients with a previous chemoradiotherapy and neutropenia, Mccarthy et al. found similar findings [29]. In our study, patients after surgery often developed $P$. aeruginosa BSI, which might be related to the previous intestinal colonization $[30,31]$. Indeed, $P$. aeruginosa often causes pneumonia and can escape from the lungs by destroying the pulmonary vascular barrier to cause BSI [32]. This might explain the pulmonary origin of $P$. aeruginosa BSI in our study. Similar to other studies [3, 33], but different from the other groups, in the present study $P$. aeruginosa often caused burn wound infection, which subsequently led to BSI. The 30 -day mortality rate was $41.5 \%$ in our study, similar to the $37 \%$ reported by other studies [30]. Thaden et al. found that $P$. aeruginosa BSI is related to increased mortality compared with other GNB BSIs, and this effect persists after adjustment for comorbidities, resistance, and treatment factors [34], thus, $P$. aeruginosa virulence might play an important role in lethality. However, by vertical comparison of the risk factors leading to death on day 2, 7, and 28 after $P$. aeruginosa BSI, Mccarthy [29] et al. found that from day-7 onwards patient comorbidities become increasingly important, suggesting that the 30-day mortality depends on the underlying disease to some extent.

\section{MDR-A. baumannii BSIs}

It is well known that ICU is a very common place to contract an infection, especially from A. baumannii, which mainly includes the following two reasons. As regard patient's factors: long hospital stay [5], experience of invasive procedures (CVC [35], surgery [1, 36], mechanical ventilation [37]), exposure to antibiotics $[1,36]$ such as carbapenems, weak immunity (previous hormone therapy [36], tumor patients with neutropenia [38]). As regard the contamination of wards [39] A. baumannii is a bacterium commonly present in ICU that is difficult to eliminate and it often spreads among the ward crowd, resulting in a high risk of $A$. baumannii colonization for patients [40,41]. Some of these aspects were also found in our study. Compared with other groups, A. baumannii group had the longest hospitalization or ICU stay, the highest total proportion of invasive operations, and exposure to more than 3 classes of antibiotics (carbapenem and piperacillin tazobactam were the main antibiotics used). Our hypothesis is that it is difficult to reduce the occurrence of $A$. baumannii infection in ICU, except for the decontamination and improvement of the awareness of the cleaning operations of the medical workers.

\section{Drug resistance}

Carbapenems were often selected for empirical treatment in our study, which is an important factor causing the onset of carbapenem-resistant $A$. baumannii, K. pneumoniae and P. aeruginosa. Carbapenems and tigacycline were rarely used in $E$. coli group when admitted to hospital, thus, the resistance rate was 
significantly lower in this group. However, with drug-resistant genes resulting in drug-resistant bacteria, they can widely spread in hospitals and communities, consequently resulting in an increased incidence of carbapenem-resistant E. coli and CR K. pneumoniae infections in China [42]. In China, ST11 has been considered as the dominant CR K. pneumoniae strain, but new ST11 CR A. baumannii is emerging [43], which is hypervirulent, multidrug resistant, and transmissible, potentially resulting a real superbacteria that could pose a serious threat to public health. The polycolisin-resistant E. coli has been found in China [42], which undoubtedly adds to the current sad situation.

\section{Prognostic analysis of MDR-A. baumannii BSIs}

Overall, previous studies found that the prognosis of $A$. baumannii BSI in ICU patients is different depending on the underlying disease, illness severity, drug resistance, therapies used, post-infection appearance and infection source. The following characteristics often lead to poor prognosis: improper initial antibiotic treatment [9, 38], comorbidities (tumours [38, 44, 45], liver cirrhosis [46], chronic obstructive pulmonary disease and chronic renal failure [37]), high drug resistance, neutropenia [38], previous high-dose hormone therapy [47], previous surgery[9], infection originated from the respiratory tract [35, 46], high SAPS score [8], Pitt score[35], APACHE II score [37, 38, 46]. However, the development of septic shock [47] and the severity of the disease are the factors most closely related to prognosis, and our study also found these two key points. A study [9] focused on ICU patients found that patients developing septic shock after MDR-A. baumannii BSI have a $23.8 \%$ higher mortality rate than patients without septic shock (82.5\% vs $58.7 \%$ ). An early study [10] grouped by APACHE II score found that the mortality of $15<$ APACHE II scores $\leq 25$ group was $14.3 \%$, and the mortality of $25<$ APACHE II scores $\leq 35$ group was 3 times of that of $15<$ APACHE II scores $\leq 25$ group. In addition, Yang et al. found that in case of $A$. baumannii BSI, the death rate of the carbapenem MICs $\geq 8 \mathrm{mg} / \mathrm{I}$ group was twice that of the MICs $\leq 48$ $\mathrm{mg} / \mathrm{l}$ group [48]. In our study, hypoalbuminemia and a previous hormone therapy were independently associated with death, suggesting that nutritional and immune statuses are very important. Because the access to colistin was limited in our hospital, common drug treatments mainly included tigecycline in combination with cefoperazone/sulbactam, and monotherapy with amikacin or sulfamethoxazole trimethoprim, but none of the monotherapies has been reported as associated with survival. In addition, in vitro treatments with sensitive antibiotics that improved the prognosis were not found.

\section{Limitations and strengths}

Some limitations are present in this study. Firstly, this was an observational research with its inherent defects. Secondly, it is a single-centre study with relatively few cases included, thus, differences between groups could not reflect a common situation worldwide. Thirdly, in the analysis of the prognosis, the adjustment for the severity of the disease and antibiotic regimen was not performed. However, this study was based on ICU patients, reducing the influence of ward difference and convenient to compare among patients of similar illness severity. The clinical characteristics of four common MDR-GNB BSIs in ICU were compared to better identify the characteristics of different BSIs. In addition, the response of vital organs or systems after infection was evaluated in order to explore the pathogenicity of MDR-A. baumannii BSI. 


\section{Conclusion}

In general, the clinical features of BSIs were significantly different among each other, especially in infection sources and reasons of ICU admission of P. aeruginosa and E. coli group. MDR-A. baumannii BSIs often occurred in patients who had long hospital stay or ICU stay and accepted various invasive operations. MDR-A. baumannii BSI had a very poor prognosis and the development of septic shock, hormone therapy, APACHE II score, high albumin level were independent risk factors affecting the prognosis. Due to the difficulty in the treatment, clinicians should pay special attention to prevent the occurrence of infection.

\section{References}

1. Wu HG, Liu WS, Zhu M, Li XX. Research and analysis of 74 bloodstream infection cases of Acinetobacter baumannii and drug resistance. Eur Rev Med Pharmacol Sci. 2018;22:1782-6.

2. Balkhair A, Al-Muharrmi Z, Al'Adawi B, Al BI, Taher HB, Al-Siyabi T et al. Prevalence and 30-day allcause mortality of carbapenem-and colistin-resistant bacteraemia caused by Acinetobacter baumannii, Pseudomonas aeruginosa, and Klebsiella pneumoniae: Description of a decade-long trend. Int J Infect Dis. 2019;85:10-5.

3. Sader HS, Huband MD, Castanheira M, Flamm RK. Pseudomonas aeruginosa Antimicrobial Susceptibility Results from Four Years (2012 to 2015) of the International Network for Optimal Resistance Monitoring Program in the United States. Antimicrob Agents Chemother. 2017;61.

4. Al-Hasan MN, Lahr BD, Eckel-Passow JE, Baddour LM. Predictive scoring model of mortality in Gramnegative bloodstream infection. Clin Microbiol Infect. 2013;19:948-54.

5. Kaye KS, Pogue JM. Infections Caused by Resistant Gram-Negative Bacteria: Epidemiology and Management. Pharmacotherapy. 2015;35:949-62.

6. Frencken JF, Wittekamp B, Plantinga NL, Spitoni C, van de Groep K, Cremer OL et al. Associations Between Enteral Colonization With Gram-Negative Bacteria and Intensive Care Unit-Acquired Infections and Colonization of the Respiratory Tract. Clin Infect Dis. 2018;66:497-503.

7. Routsi C, Pratikaki M, Platsouka E, Sotiropoulou C, Papas V, Pitsiolis T et al. Risk factors for carbapenem-resistant Gram-negative bacteremia in intensive care unit patients. Intensive Care Med. 2013;39:1253-61.

8. Russo A, Giuliano S, Ceccarelli G, Alessandri F, Giordano A, Brunetti G et al. Comparison of Septic Shock Due to Multidrug-Resistant Acinetobacter baumannii or Klebsiella pneumoniae Carbapenemase-Producing K. pneumoniae in Intensive Care Unit Patients. Antimicrob Agents Chemother. 2018;62:e2517-62.

9. Russo A, Bassetti M, Ceccarelli G, Carannante N, Losito AR, Bartoletti M et al. Bloodstream infections caused by carbapenem-resistant Acinetobacter baumannii: Clinical features, therapy and outcome from a multicenter study. J Infect. 2019;79:130-8. 
10. Lee YT, Kuo SC, Yang SP, Lin YT, Tseng FC, Chen TL et al. Impact of Appropriate Antimicrobial Therapy on Mortality Associated With Acinetobacter baumannii Bacteremia: Relation to Severity of Infection. Clin Infect Dis. 2012;55:209-15.

11. Blot S, Vandewoude K, Hoste E, De Waele J, Kint K, Rosiers F et al. Absence of excess mortality in critically ill patients with nosocomial Escherichia coli bacteremia. Infect Control Hosp Epidemiol. 2003;24:912-5.

12. Zhang Q, Gao H, Li D, Li Z, Qi S, Zheng S et al. Clinical outcome of Escherichia coli bloodstream infection in cancer patients with/without biofilm formation: a single-center retrospective study. Infect Drug Resist. 2019;12:359-71.

13. Papadimitriou-Olivgeris M, Fligou F, Spiliopoulou A, Koutsileou K, Kolonitsiou F, Spyropoulou A et al. Risk factors and predictors of carbapenem-resistant Pseudomonas aeruginosa and Acinetobacter baumannii mortality in critically ill bacteraemic patients over a 6-year period (2010-15): antibiotics do matter. J Med Microbiol. 2017;66:1092-101.

14. Singer M, Deutschman CS, Seymour CW, Shankar-Hari M, Annane D, Bauer M et al. The Third International Consensus Definitions for Sepsis and Septic Shock (Sepsis-3). JAMA. 2016;315:801-10.

15. Magiorakos A, Srinivasan A, Carey RB, Carmeli Y, Falagas ME, Giske CG et al. Multidrug-resistant, extensively drug-resistant and pandrug-resistant bacteria: an international expert proposal for interim standard definitions for acquired resistance. Clin Microbiol Infect. 2012;18:268-81.

16. Liu P, Li X, Luo M, Xu X, Su K, Chen S et al. Risk Factors for Carbapenem-Resistant Klebsiella pneumoniae Infection: A Meta-Analysis. Microb Drug Resist. 2018;24:190-8.

17. Li Y, Shen H, Zhu C, Yu Y. Carbapenem-Resistant Klebsiella pneumoniae Infections among ICU Admission Patients in Central China: Prevalence and Prediction Model. Biomed Res Int. 2019;2019:9767313.

18. Bertolini G, Nattino G, Tascini C, Poole D, Viaggi B, Carrara G et al. Mortality attributable to different Klebsiella susceptibility patterns and to the coverage of empirical antibiotic therapy: a cohort study on patients admitted to the ICU with infection. Intensive Care Med. 2018;44:1709-19.

19. Gorrie CL, Mirceta M, Wick RR, Edwards DJ, Thomson NR, Strugnell RA et al. Gastrointestinal Carriage Is a Major Reservoir of Klebsiella pneumoniae Infection in Intensive Care Patients. Clin Infect Dis. 2017;65:208-15.

20. Martin RM, Cao J, Brisse S, Passet V, Wu W, Zhao L et al. Molecular Epidemiology of Colonizing and Infecting Isolates of Klebsiella pneumoniae. mSphere. 2016;1:e216-61.

21. Frencken JF, Wittekamp B, Plantinga NL, Spitoni C, van de Groep K, Cremer OL et al. Associations Between Enteral Colonization With Gram-Negative Bacteria and Intensive Care Unit-Acquired Infections and Colonization of the Respiratory Tract. Clin Infect Dis. 2018;66:497-503.

22. Oostdijk EA, de Smet AM, Kesecioglu J, Bonten MJ. The role of intestinal colonization with gramnegative bacteria as a source for intensive care unit-acquired bacteremia. Crit Care Med. 2011;39:9616. 
23. Wittekamp BH, Plantinga NL, Cooper BS, Lopez-Contreras J, Coll P, Mancebo J et al. Decontamination Strategies and Bloodstream Infections With Antibiotic-Resistant Microorganisms in Ventilated Patients: A Randomized Clinical Trial. JAMA. 2018,320:2087-98.

24. Bertolini G, Nattino G, Tascini C, Poole D, Viaggi B, Carrara G et al. Mortality attributable to different Klebsiella susceptibility patterns and to the coverage of empirical antibiotic therapy: a cohort study on patients admitted to the ICU with infection. Intensive Care Med. 2018;44:1709-19.

25. Vila J, Saez-Lopez E, Johnson JR, Romling U, Dobrindt U, Canton R et al. Escherichia coli: an old friend with new tidings. FEMS Microbiol Rev. 2016;40:437-63.

26. Koksal I, Yilmaz G, Unal S, Zarakolu P, Korten V, Mulazimoglu L et al. Epidemiology and susceptibility of pathogens from SMART 2011-12 Turkey: evaluation of hospital-acquired versus communityacquired urinary tract infections and ICU- versus non-ICU-associated intra-abdominal infections. J Antimicrob Chemother. 2017;72:1364-72.

27. Bou-Antoun S, Davies J, Guy R, Johnson AP, Sheridan EA, Hope RJ. Descriptive epidemiology of Escherichia coli bacteraemia in England, April 2012 to March 2014. Euro Surveill. 2016;21.

28. Ajao AO, Johnson JK, Harris AD, Zhan M, McGregor JC, Thom KA et al. Risk of acquiring extendedspectrum beta-lactamase-producing Klebsiella species and Escherichia coli from prior room occupants in the intensive care unit. Infect Control Hosp Epidemiol. 2013;34:453-8.

29. McCarthy KL, Paterson DL. Long-term mortality following Pseudomonas aeruginosa bloodstream infection. J Hosp Infect. 2017;95:292-9.

30. Juan C, Pena C, Oliver A. Host and Pathogen Biomarkers for Severe Pseudomonas aeruginosa Infections. J Infect Dis. 2017;215:S44-51.

31. Gomez-Zorrilla S, Camoez M, Tubau F, Canizares R, Periche E, Dominguez MA et al. Prospective observational study of prior rectal colonization status as a predictor for subsequent development of Pseudomonas aeruginosa clinical infections. Antimicrob Agents Chemother. 2015;59:5213-9.

32. Berube BJ, Rangel SM, Hauser AR. Pseudomonas aeruginosa: breaking down barriers. Current Genetics. 2016;62:109-13.

33. Ramirez-Blanco CE, Ramirez-Rivero CE, Diaz-Martinez LA, Sosa-Avila LM. Infection in burn patients in a referral center in Colombia. Burns. 2017;43:642-53.

34. Thaden JT, Park LP, Maskarinec SA, Ruffin F, Fowler VJ, van Duin D. Results from a 13-Year Prospective Cohort Study Show Increased Mortality Associated with Bloodstream Infections Caused by Pseudomonas aeruginosa Compared to Other Bacteria. Antimicrob Agents Chemother. 2017;61.

35. Ng TM, Teng CB, Lye DC, Apisarnthanarak A. A multicenter case-case control study for risk factors and outcomes of extensively drug-resistant Acinetobacter baumannii bacteremia. Infect Control Hosp Epidemiol. 2014;35:49-55.

36. Garcia-Garmendia JL, Ortiz-Leyba C, Garnacho-Montero J, Jimenez-Jimenez FJ, Perez-Paredes C, Barrero-Almodovar AE et al. Risk factors for Acinetobacter baumannii nosocomial bacteremia in critically ill patients: a cohort study. Clin Infect Dis. 2001;33:939-46. 
37. Brotfain E, Borer A, Koyfman L, Saidel-Odes L, Frenkel A, Gruenbaum SE et al. Multidrug Resistance Acinetobacter Bacteremia Secondary to Ventilator-Associated Pneumonia: Risk Factors and Outcome. J Intensive Care Med. 2017;32:528-34.

38. Wang X, Zhang L, Sun A, Yang X, Sang W, Jiang Y et al. Acinetobacter baumannii bacteraemia in patients with haematological malignancy: a multicentre retrospective study from the Infection Working Party of Jiangsu Society of Hematology. Eur J Clin Microbiol Infect Dis. 2017;36:1073-81.

39. Cisneros JM, Rodríguez-Baño J. Nosocomial bacteremia due to Acinetobacter baumannii: epidemiology, clinical features and treatment. Clin Microbiol Infect. 2002;8:687-93.

40. Latibeaudiere R, Rosa R, Laowansiri P, Arheart K, Namias N, Munoz-Price LS. Surveillance cultures growing carbapenem-Resistant Acinetobacter baumannii predict the development of clinical infections: a retrospective cohort study. Clin Infect Dis. 2015;60:415-22.

41. Wisplinghoff $H$, Perbix W, Seifert $H$. Risk factors for nosocomial bloodstream infections due to Acinetobacter baumannii: a case-control study of adult burn patients. Clin Infect Dis. 1999;28:59-66.

42. Li Y, Sun QL, Shen Y, Zhang Y, Yang JW, Shu LB et al. Rapid Increase in Prevalence of CarbapenemResistant Enterobacteriaceae (CRE) and Emergence of Colistin Resistance Gene mcr-1 in CRE in a Hospital in Henan, China. J Clin Microbiol. 2018;56.

43. Gu D, Dong N, Zheng Z, Lin D, Huang M, Wang L et al. A fatal outbreak of ST11 carbapenem-resistant hypervirulent Klebsiella pneumoniae in a Chinese hospital: a molecular epidemiological study. Lancet Infect Dis. 2018;18:37-46.

44. Busani S, Serafini G, Mantovani E, Venturelli C, Giannella M, Viale P et al. Mortality in Patients With Septic Shock by Multidrug Resistant Bacteria: Risk Factors and Impact of Sepsis Treatments. J Intensive Care Med. 2019;34:48-54.

45. Freire MP, de Oliveira Garcia D, Garcia CP, Campagnari Bueno MF, Camargo CH, Kono Magri ASG et al. Bloodstream infection caused by extensively drug-resistant Acinetobacter baumannii in cancer patients: high mortality associated with delayed treatment rather than with the degree of neutropenia. Clin Microbiol Infect. 2016;22:352-8.

46. Liu CP, Shih SC, Wang NY, Wu AY, Sun FJ, Chow SF et al. Risk factors of mortality in patients with carbapenem-resistant Acinetobacter baumannii bacteremia. J Microbiol Immunol Infect. 2016;49:93440.

47. Ballouz T, Aridi J, Afif C, Irani J, Lakis C, Nasreddine R et al. Risk Factors, Clinical Presentation, and Outcome of Acinetobacter baumannii Bacteremia. Front Cell Infect Microbiol. 2017;7:156.

48. Yang YS, Wang YC, Kuo SC, Chen CT, Liu CP, Liu YM et al. Multicenter Study of the Relationship between Carbapenem MIC Values and Clinical Outcome of Patients with Acinetobacter Bacteremia. Antimicrob Agents Chemother. 2017;61.

\section{Tables}


TABLE 1 Comparison of clinical features of the four kinds of BSIs

\begin{tabular}{|c|c|c|c|c|c|}
\hline Variables & $\begin{array}{l}\text { MDR- } A \text {. } \\
\text { baumanni } \\
(\mathrm{n}=96)\end{array}$ & $\begin{array}{l}\text { MDR- } K \text {. } \\
\text { pneumoniae } \\
(\mathrm{n}=147)\end{array}$ & $\begin{array}{l}\text { MDR- } P \text {. } \\
\text { aeruginosa } \\
(\mathrm{n}=65)\end{array}$ & $\begin{array}{l}\text { MDR-E. } \\
\text { coli } \\
(\mathrm{n}=76)\end{array}$ & $\mathrm{P}$ \\
\hline Age, mean \pm SD (years) & $66.7 \pm 16.1$ & $66.5 \pm 13.8$ & $62.1 \pm 14.9$ & $\begin{array}{l}60.7 \pm \\
11.3\end{array}$ & 0.002 \\
\hline APACHE $\square$ scores & $26.1 \pm 3.7$ & $27.0 \pm 3.9$ & $25.9 \pm 4.2$ & $25.6 \pm 5.1$ & 0.072 \\
\hline Male sex & $63(65.6 \%)$ & $100(68.03 \%)$ & $42(64.6 \%)$ & $\begin{array}{l}44 \\
(57.9 \%)\end{array}$ & 0.514 \\
\hline \multicolumn{6}{|l|}{ Underlying diseases } \\
\hline Diabetes & $26(27.1 \%)$ & $40(27.2 \%)$ & $15(23.1 \%)$ & $\begin{array}{l}22 \\
(28.9 \%)\end{array}$ & 0.884 \\
\hline Angiocardiopathy & $57(59.4 \%)$ & $78(53.1 \%)$ & $28(43.1 \%)$ & $\begin{array}{l}32 \\
(42.1 \%)\end{array}$ & 0.073 \\
\hline Cerebrovascular disease & $32(33.4 \%)$ & $48(32.7 \%)$ & $20(30.8 \%)$ & $\begin{array}{l}13 \\
(17.1 \%)\end{array}$ & 0.070 \\
\hline Chronic lung disease & $23(24.0 \%)$ & 27 (18.4\%) & $5(7.7 \%)$ & $5(6.6 \%)$ & 0.003 \\
\hline Chronic kidney diseases & $24(25.0 \%)$ & $15(10.2 \%)$ & $4(6.2 \%)$ & $4(5.3 \%)$ & $<0.001$ \\
\hline Chronic liver disease & 7 (7.3\%) & $5(3.4 \%)$ & $0(0.0 \%)$ & $4(5.3 \%)$ & 0.132 \\
\hline Rheumatic disease & $10(10.4 \%)$ & $11(7.5 \%)$ & $4(6.2 \%)$ & $5(6.6 \%)$ & 0.721 \\
\hline Neoplasm & $11(11.5 \%)$ & $21(14.3 \%)$ & $15(23.1 \%)$ & $\begin{array}{l}13 \\
(17.1 \%)\end{array}$ & 0.228 \\
\hline Leukemia & $5(5.2 \%)$ & $5(3.4 \%)$ & $4(6.2 \%)$ & $3(4.0 \%)$ & 0.800 \\
\hline Other & 13 (13.5\%) & $6(4.1 \%)$ & $4(6.2 \%)$ & $3(4.0 \%)$ & 0.022 \\
\hline \multicolumn{6}{|l|}{ Cause of ICU admission } \\
\hline Severe pneumonia & $62(64.6 \%)$ & $82(55.8 \%)$ & $32(49.2 \%)$ & $\begin{array}{l}18 \\
(23.7 \%)\end{array}$ & $<0.001$ \\
\hline Urinary system infection & $6(6.3 \%)$ & $8(5.4 \%)$ & $3(4.6 \%)$ & $\begin{array}{l}16 \\
(21.1 \%)\end{array}$ & $<0.001$ \\
\hline Abdominal infection & $8(8.3 \%)$ & $24(16.3 \%)$ & $10(15.4 \%)$ & $\begin{array}{l}28 \\
(36.8 \%)\end{array}$ & $<0.001$ \\
\hline Other infections & $6(6.3 \%)$ & $6(4.1 \%)$ & $3(4.6 \%)$ & $1(1.3 \%)$ & 0.453 \\
\hline Shock & $50(52.1 \%)$ & $65(44.2 \%)$ & 27 (41.5\%) & $\begin{array}{l}50 \\
(65.8 \%)\end{array}$ & 0.009 \\
\hline Respiratory failure & $61(63.5 \%)$ & $98(66.7 \%)$ & $49(75.4 \%)$ & $\begin{array}{l}29 \\
(38.2 \%)\end{array}$ & $<0.001$ \\
\hline Renal failure & $17(17.7 \%)$ & $14(9.5 \%)$ & $13(20.0 \%)$ & $\begin{array}{l}24 \\
(31.6 \%)\end{array}$ & $<0.001$ \\
\hline Liver failure & $6(6.3 \%)$ & $5(3.4 \%)$ & $3(4.6 \%)$ & $2(2.6 \%)$ & 0.628 \\
\hline Trauma & $12(12.5 \%)$ & $18(12.2 \%)$ & $5(7.7 \%)$ & $\begin{array}{l}10 \\
(13.2 \%)\end{array}$ & 0.737 \\
\hline Extensive burns & $3(3.1 \%)$ & $0(0.0 \%)$ & $6(9.2 \%)$ & $0(0.0 \%)$ & $<0.001$ \\
\hline Stroke & $6(6.2 \%)$ & $15(10.2 \%)$ & $3(4.6 \%)$ & $2(2.6 \%)$ & 0.149 \\
\hline Postoperation & $10(10.4 \%)$ & $13(8.8 \%)$ & $16(24.6 \%)$ & $\begin{array}{l}22 \\
(28.9 \%)\end{array}$ & $<0.001$ \\
\hline $\begin{array}{l}\text { After cardiopulmonary } \\
\text { resuscitation }\end{array}$ & $8(8.3 \%)$ & $15(10.2 \%)$ & $2(3.1 \%)$ & $4(5.3 \%)$ & 0.262 \\
\hline \multicolumn{6}{|l|}{ Source of infection } \\
\hline CVC-related bacteremia & $17(17.7 \%)$ & $20(13.6 \%)$ & $6(9.2 \%)$ & $3(4.0 \%)$ & 0.037 \\
\hline Pneumonia & $34(35.4 \%)$ & 58 (39.5\%) & $12(18.5 \%)$ & $2(2.6 \%)$ & $<0.001$ \\
\hline Intra-abdominal & $11(11.5 \%)$ & $24(16.3 \%)$ & $12(18.5 \%)$ & $\begin{array}{l}40 \\
(52.6 \%)\end{array}$ & $<0.001$ \\
\hline Urinary tract & $3(3.1 \%)$ & $10(6.8 \%)$ & $4(6.2 \%)$ & $\begin{array}{l}22 \\
(29.0 \%)\end{array}$ & $<0.001$ \\
\hline
\end{tabular}




\begin{tabular}{|c|c|c|c|c|c|}
\hline Skin or soft tissue & $3(3.1 \%)$ & $7(4.8 \%)$ & $10(15.4 \%)$ & $1(1.3 \%)$ & 0.001 \\
\hline Primary bacteremia & $28(29.2 \%)$ & $28(19.1 \%)$ & $21(32.3 \%)$ & $8(10.5 \%)$ & 0.004 \\
\hline \multicolumn{6}{|l|}{$\begin{array}{l}\text { Previous microorganism } \\
\text { colonization/infection }\end{array}$} \\
\hline The same kind & 45 (46.9\%) & $95(64.6 \%)$ & $33(50.8 \%)$ & $\begin{array}{l}27 \\
(35.5 \%)\end{array}$ & $<0.001$ \\
\hline Other bacteria & $47(49.0 \%)$ & $62(42.2 \%)$ & $29(44.6 \%)$ & $8(10.5 \%)$ & $<0.001$ \\
\hline Fungus & $18(18.8 \%)$ & $12(8.1 \%)$ & $4(6.2 \%)$ & $4(5.3 \%)$ & 0.008 \\
\hline \multicolumn{6}{|l|}{ Invasive procedures } \\
\hline Previous surgery & 27 (28.1\%) & $55(37.4 \%)$ & $30(46.2 \%)$ & $\begin{array}{l}28 \\
(36.8 \%)\end{array}$ & 0.134 \\
\hline CVC & $78(81.3 \%)$ & $98(66.7 \% \square$ & $45(69.2 \%)$ & 30 & $<0.001$ \\
\hline Abdominal drainage & $17(17.7 \%)$ & $25(17.0 \%)$ & $15(23.1 \%)$ & $\begin{array}{l}19 \\
(25.0 \%)\end{array}$ & 0.437 \\
\hline Thoracic drainage & 15 (15.6\%) & $14(9.5 \%)$ & $8(12.3 \%)$ & $5(6.6 \%)$ & 0.254 \\
\hline Invasive mechanical ventilator & 77 (80.2\%) & $96(65.3 \%)$ & $39(60.0 \%)$ & $\begin{array}{l}18 \\
(23.7 \%)\end{array}$ & $<0.001$ \\
\hline Tracheostomy & $34(35.4 \%)$ & $48(32.7 \%)$ & $10(15.4 \%)$ & $\begin{array}{l}13 \\
(17.1 \%)\end{array}$ & 0.003 \\
\hline CRRT & $23(24.0 \%)$ & $23(15.7 \%)$ & $5(7.7 \%)$ & $8(10.5 \%)$ & 0.021 \\
\hline $\begin{array}{l}\text { Nasogastric tube or } \\
\text { nasointestinal tube }\end{array}$ & $90(93.8 \%)$ & $123(83.7 \%)$ & $46(70.8 \%)$ & $\begin{array}{l}28 \\
(36.8 \%)\end{array}$ & $<0.001$ \\
\hline Urinary catheter & $91(94.8 \%)$ & 117 (79.6\%) & $52(80.0 \%)$ & $\begin{array}{l}31 \\
(40.8 \%)\end{array}$ & $<0.001$ \\
\hline Other & $11(11.5 \%)$ & $18(12.2 \%)$ & $5(7.7 \%)$ & $8(10.5 \%)$ & 0.801 \\
\hline $\begin{array}{l}\text { Length of ICU stay, mean } \pm \text { SD } \\
\text { (days) }\end{array}$ & $28.8 \pm 29.8$ & $13.8 \pm 7.4$ & $9.6 \pm 9.3$ & $5.4 \pm 9.6$ & $<0.001$ \\
\hline median (Q1-Q3) & $\begin{array}{l}18.0(9.0- \\
35.0)\end{array}$ & $14.0(9.0-17.0)$ & $7.0(4.0-12.0)$ & $\begin{array}{l}1.0(1.0- \\
3.2)\end{array}$ & $<0.001$ \\
\hline $\begin{array}{l}\text { Length of hospitalization, mean } \pm \\
\text { SD (days) }\end{array}$ & $42.6 \pm 36.0$ & $23.2 \pm 10.0$ & $18.8 \pm 13.1$ & $8.8 \pm 10.5$ & $<0.001$ \\
\hline median (Q1-Q3) & $\begin{array}{l}29.0(19.0- \\
53.5)\end{array}$ & $21.0(18.0-29.0)$ & $17.0(9.0-25.0)$ & $\begin{array}{l}4.5(1.8- \\
13.0)\end{array}$ & $<0.001$ \\
\hline Albumin, mean \pm SD $(\mathrm{g} / \mathrm{l})$ & $27.0 \pm 4.5$ & $27.8 \pm 4.1$ & $28.7 \pm 3.5$ & $26.1 \pm 4.8$ & $<0.001$ \\
\hline Prior chemotherapy or radiotherapy & $7(7.3 \%)$ & $9(6.1 \%)$ & $10(15.4 \%)$ & $3(4.0 \%)$ & 0.056 \\
\hline Prior steroid treatment & $31(32.3 \%)$ & $46(31.3 \%)$ & $20(30.8 \%)$ & $8(10.5 \%)$ & 0.004 \\
\hline $\begin{array}{l}\text { Prior antibiotic therapy (1-2 } \\
\text { categories) }\end{array}$ & $42(43.8 \%)$ & $62(42.2 \%)$ & $38(58.5 \%)$ & $\begin{array}{l}33 \\
(43.4 \%)\end{array}$ & 0.151 \\
\hline $\begin{array}{l}\text { Prior antibiotic therapy ( } \geq 3 \\
\text { categories) }\end{array}$ & $51(54.8 \%)$ & $82(55.8 \%)$ & $26(40.0 \%)$ & $9(11.8 \%)$ & $<0.001$ \\
\hline Neutropenia (prior to BSI) & $6(6.3 \%)$ & $15(10.2 \%)$ & $10(15.4 \%)$ & $4(5.3 \%)$ & 0.132 \\
\hline Parenteral nutrition & $24(25.0 \%)$ & $27(18.4 \%)$ & $16(24.6 \%)$ & $5(6.6 \%)$ & 0.010 \\
\hline 28-day mortality & $69(71.9 \%)$ & $93(63.3 \%)$ & 27 (41.5\%) & $\begin{array}{l}29 \\
(38.2 \%)\end{array}$ & $<0.001$ \\
\hline
\end{tabular}

BSI: bloodstream infection; ICU: intensive care unit; SD: standard deviation; Q1: 1st quartile; Q3: 3rd quartile; APACHE: cute physiology and chronic health evaluation; CVC: central venous catheter; CRRT: continuous renal replacement therapy. 
TABLE 2 Comparison of drug resistance

\begin{tabular}{|c|c|c|c|c|}
\hline Antimicrobial agent & $\begin{array}{c}\text { MDR- } A \text {. } \\
\text { baumannii } \\
(\mathrm{n}=96)\end{array}$ & $\begin{array}{c}\text { MDR- } K \text {. } \\
\text { pneumoniae } \\
(\mathrm{n}=147)\end{array}$ & $\begin{array}{c}\text { MDR- } P \text {. } \\
\text { aeruginosa } \\
(\mathrm{n}=65)\end{array}$ & $\begin{array}{c}\text { MDR-E. } \\
\text { coli } \\
(\mathrm{n}=72)\end{array}$ \\
\hline & $\mathrm{R}(\%)$ & $\mathrm{R}(\%)$ & R (\%) & R (\%) \\
\hline Imipenem & 95.8 & 75.5 & 44.6 & 9.2 \\
\hline Piperacillin tazobactam & 97.9 & 85.0 & 23.1 & 17.1 \\
\hline Ceftazidime & 94.8 & 68.0 & 30.8 & 31.6 \\
\hline Levofloxacin & 89.6 & 89.1 & 30.8 & 77.6 \\
\hline Amikacin & 53.1 & 65.3 & 27.7 & 9.0 \\
\hline $\begin{array}{l}\text { Sulfamethoxazole } \\
\text { trimethoprim }\end{array}$ & 64.6 & 80.2 & 80.0 & 67.1 \\
\hline Tigecycline & 83.3 & 31.3 & 86.2 & 0.0 \\
\hline
\end{tabular}


TABLE 3 Univariate and multivariate Cox regression analysis about factors associated with 28-day mortality in MDR-A. baumannii BSIs

\begin{tabular}{|c|c|c|c|c|c|c|c|c|c|c|}
\hline \multirow[t]{3}{*}{ Variables } & \multirow{3}{*}{$\begin{array}{l}\text { Survivor } \\
(\mathrm{n}=27)\end{array}$} & \multirow{3}{*}{$\begin{array}{l}\text { Non- } \\
\text { Survivor } \\
(\mathrm{n}=69)\end{array}$} & \multicolumn{4}{|c|}{ univariate analysis } & \multicolumn{4}{|c|}{ multivariate analysis } \\
\hline & & & \multirow[t]{2}{*}{ HR } & \multicolumn{2}{|c|}{ 95\% CI } & \multirow[t]{2}{*}{$P$} & \multirow[t]{2}{*}{ HR } & \multicolumn{2}{|c|}{ 95\% CI } & \multirow[t]{2}{*}{$\mathrm{P}$} \\
\hline & & & & lower & upper & & & lower & upper & \\
\hline Age, mean \pm SD (years) & $\begin{array}{l}62.1 \pm \\
20.9\end{array}$ & $\begin{array}{l}68.4 \pm \\
13.5\end{array}$ & 1.008 & 0.994 & 1.022 & 0.288 & & & & \\
\hline Female sex & $\begin{array}{l}10 \\
(37.0 \%)\end{array}$ & $\begin{array}{l}23 \\
(33.3 \%)\end{array}$ & 0.950 & 0.576 & 1.567 & 0.840 & & & & \\
\hline APACHE』scores & $\begin{array}{l}27.1 \pm \\
3.2\end{array}$ & $\begin{array}{l}24.1 \pm \\
3.7\end{array}$ & 1.141 & 1.064 & 1.223 & 0.000 & 1.131 & 1.039 & 1.231 & 0.005 \\
\hline \multicolumn{11}{|l|}{ Underlying diseases } \\
\hline Diabetes & $\begin{array}{l}6 \\
(22.2 \%)\end{array}$ & $\begin{array}{l}20 \\
(29.0 \%)\end{array}$ & 1.060 & 0.630 & 1.783 & 0.827 & & & & \\
\hline Angiocardiopathy & $\begin{array}{l}17 \\
(63.0 \%)\end{array}$ & $\begin{array}{l}40 \\
(58.0 \%)\end{array}$ & 0.818 & 0.507 & 1.320 & 0.411 & & & & \\
\hline $\begin{array}{l}\text { Cerebrovascular } \\
\text { disease }\end{array}$ & $\begin{array}{l}13 \\
(48.1 \%)\end{array}$ & $\begin{array}{l}19 \\
(27.5 \%)\end{array}$ & 0.545 & 0.320 & 0.931 & 0.026 & & & & \\
\hline Chronic lung disease & $\begin{array}{l}5 \\
(18.5 \%)\end{array}$ & $\begin{array}{l}18 \\
(26.1 \%)\end{array}$ & 1.265 & 0.738 & 2.167 & 0.393 & & & & \\
\hline Chronic kidney diseases & $\begin{array}{l}4 \\
(14.8 \%)\end{array}$ & $\begin{array}{l}20 \\
(29.0 \%)\end{array}$ & 1.095 & 0.650 & 1.846 & 0.733 & & & & \\
\hline Chronic liver disease & $\begin{array}{l}1 \\
(3.7 \%)\end{array}$ & $\begin{array}{l}6 \\
(8.7 \%)\end{array}$ & 1.324 & 0.573 & 3.062 & 0.512 & & & & \\
\hline Rheumatic disease & $\begin{array}{l}2 \\
(7.4 \%)\end{array}$ & $\begin{array}{l}8 \\
(11.6 \%)\end{array}$ & 1.351 & 0.646 & 2.826 & 0.424 & & & & \\
\hline Neoplasm & $\begin{array}{l}3 \\
(11.1 \%)\end{array}$ & $\begin{array}{l}8 \\
(11.6 \%)\end{array}$ & 0.942 & 0.450 & 1.970 & 0.874 & & & & \\
\hline Leukemia & $\begin{array}{l}4 \\
(14.8 \%)\end{array}$ & $\begin{array}{l}1 \\
(1.4 \%)\end{array}$ & 0.176 & 0.024 & 1.272 & 0.085 & & & & \\
\hline \multicolumn{11}{|l|}{ Invasive procedures } \\
\hline Previous surgery & $\begin{array}{l}8 \\
(29.6 \%)\end{array}$ & $\begin{array}{l}19 \\
(27.5 \%)\end{array}$ & 0.954 & 0.563 & 1.619 & 0.863 & & & & \\
\hline $\mathrm{CVC}$ & $\begin{array}{l}19 \\
(70.4 \%)\end{array}$ & $\begin{array}{l}59 \\
(85.5 \%)\end{array}$ & 1.492 & 0.763 & 2.920 & 0.242 & & & & \\
\hline Abdominal drainage & $\begin{array}{l}3 \\
(11.1 \%)\end{array}$ & $\begin{array}{l}14 \\
(20.3 \%)\end{array}$ & 1.173 & 0.652 & 2.110 & 0.594 & & & & \\
\hline Thoracic drainage & $\begin{array}{l}3 \\
(11.1 \%)\end{array}$ & $\begin{array}{l}12 \\
(17.4 \%)\end{array}$ & 1.178 & 0.632 & 2.196 & 0.606 & & & & \\
\hline $\begin{array}{l}\text { Invasive mechanical } \\
\text { ventilator }\end{array}$ & $\begin{array}{l}20 \\
(74.1 \%)\end{array}$ & $\begin{array}{l}57 \\
(82.6 \%)\end{array}$ & 1.425 & 0.764 & 2.657 & 0.265 & & & & \\
\hline Tracheostomy & $\begin{array}{l}13 \\
(48.1 \%)\end{array}$ & $\begin{array}{l}21 \\
(30.4 \%)\end{array}$ & 0.693 & 0.414 & 1.160 & 0.693 & & & & \\
\hline CRRT & $\begin{array}{l}6 \\
(22.2 \%)\end{array}$ & $\begin{array}{l}17 \\
(24.6 \%)\end{array}$ & 1.121 & 0.648 & 1.940 & 0.682 & & & & \\
\hline $\begin{array}{l}\text { Prior antibiotic therapy } \\
\text { ( } \geq 3 \text { categories) }\end{array}$ & $\begin{array}{l}16 \\
(61.5 \%)\end{array}$ & $\begin{array}{l}35 \\
(52.2 \%)\end{array}$ & 0.871 & 0.539 & 1.408 & 0.574 & & & & \\
\hline $\begin{array}{l}\text { Neutropenia (prior to } \\
\text { BSI) }\end{array}$ & $\begin{array}{l}1 \\
(3.7 \%)\end{array}$ & $\begin{array}{l}5 \\
(7.2 \%)\end{array}$ & 1.251 & 0.502 & 3.114 & 0.631 & & & & \\
\hline Prior steroid treatment & $\begin{array}{l}5 \\
(18.5 \%)\end{array}$ & $\begin{array}{l}27 \\
(39.1 \%)\end{array}$ & 1.982 & 1.213 & 3.238 & 0.006 & 2.183 & 1.242 & 3.840 & 0.007 \\
\hline Albumin , mean \pm SD (g/l) & $\begin{array}{l}30.0 \pm \\
4.9\end{array}$ & $\begin{array}{l}25.7 \pm \\
3.6\end{array}$ & 0.910 & 0.861 & 0.962 & 0.001 & 0.918 & 0.861 & 0.979 & 0.010 \\
\hline $\begin{array}{l}\text { Sensitive antibiotic } \\
\text { therapy }\end{array}$ & $\begin{array}{l}9 \\
(33.3 \%)\end{array}$ & $\begin{array}{l}23 \\
(33.3 \%)\end{array}$ & 0.852 & 0.516 & 1.407 & 0.532 & & & & \\
\hline $\begin{array}{l}\text { Length of ICU stay (prior } \\
\text { to BSI), median (Q1-Q3) }\end{array}$ & $\begin{array}{l}18.0 \\
(8.0-\end{array}$ & $\begin{array}{l}17.0 \\
(9.5-\end{array}$ & 0.996 & 0.987 & 1.004 & 0.328 & & & & \\
\hline
\end{tabular}


49.0) 29.0)

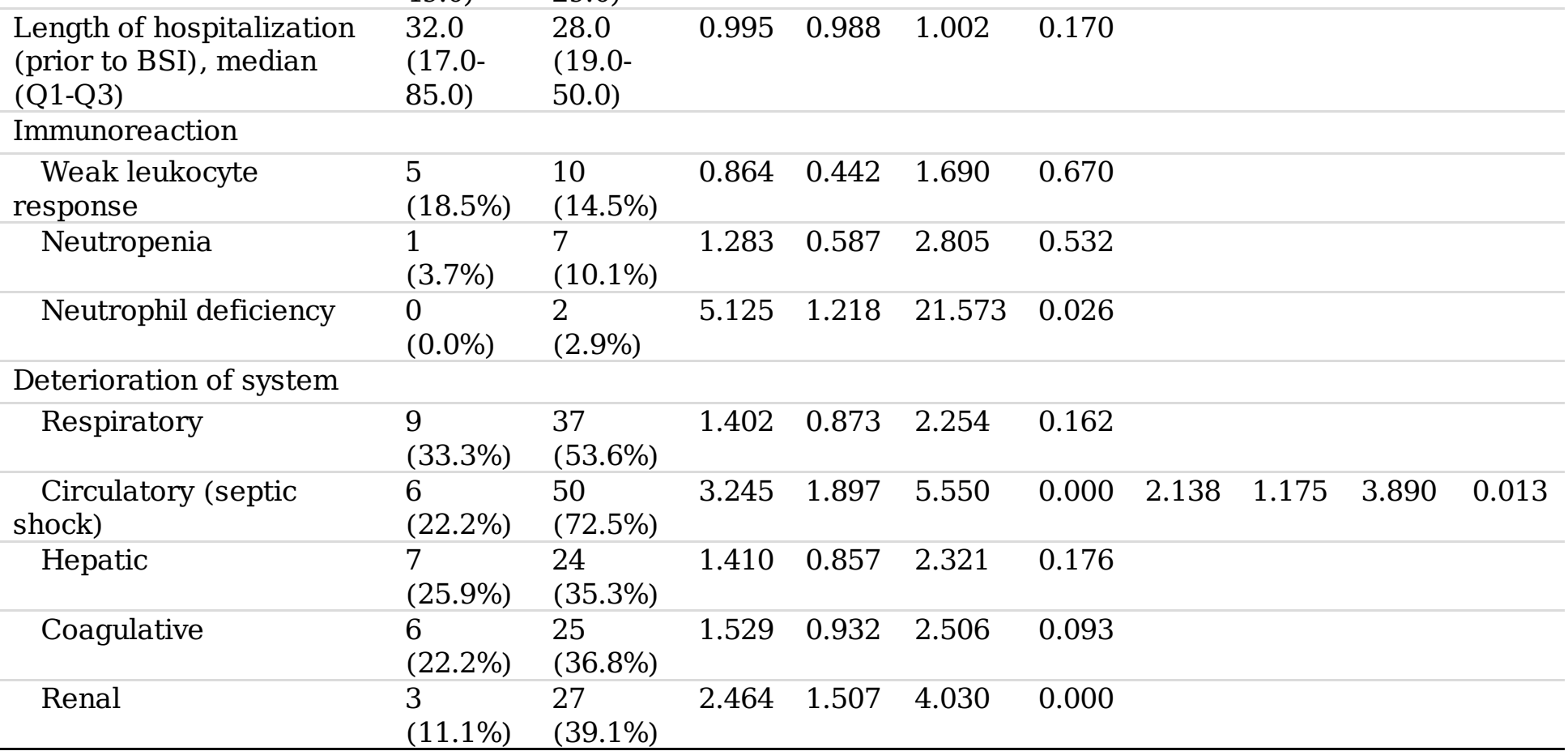

CI: confidence interval; HR: hazard ratio; SD: standard deviation; BSI: bloodstream infection; Q1: 1st quartile; Q3: 3rd quartile; APACHE: cute physiology and chronic health evaluation; CVC: central venous catheter; CRRT: continuous renal replacement therapy; ICU: intensive care unit.

\section{Declarations}

Conflict of interest: The authors declare that they have no conflict of interest.

Source of funding: This work was supported by the Lianyungang Health Commission Plan Funding Project of Jiangsu province (QN1804).

Acknowledgements: We thank to the the nurses in our department, also thank to the staff of all microbiology laboratories in our hospital.

Ethical Standards and Approval: The study was conducted in accordance with the ethical standards of the Helsinki declaration and its later amendments and approved through Research Ethics Committee of the Affiliated Lianyungang Hospital of Xuzhou Medical University in China.

\section{Figures}



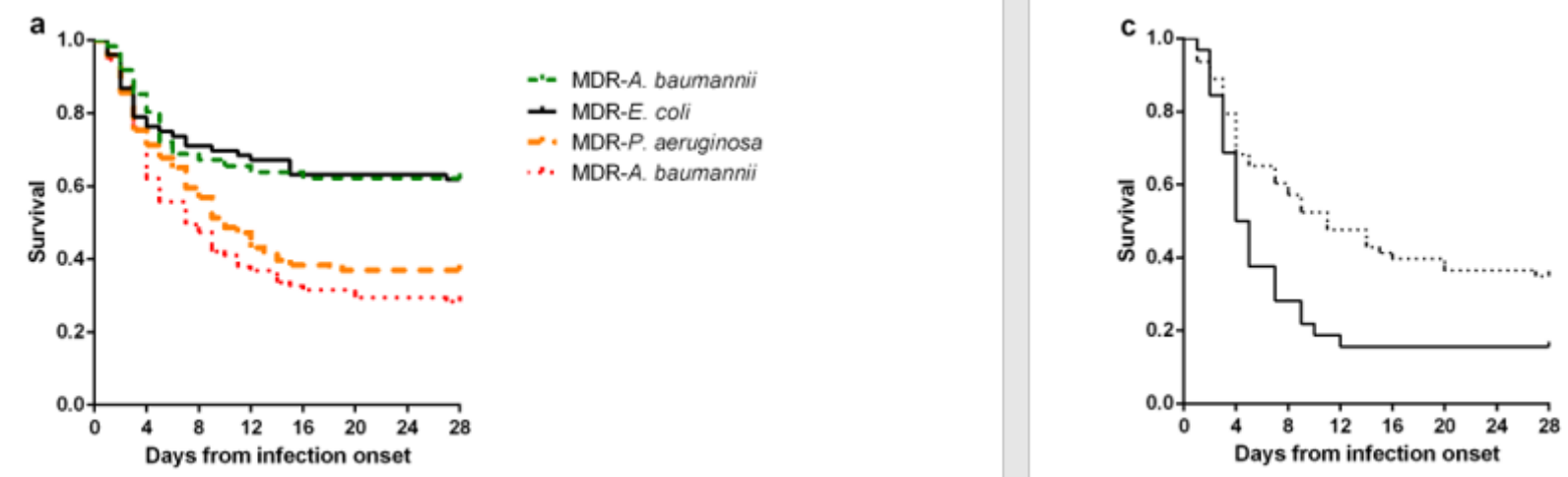

... Prior steroid treatment

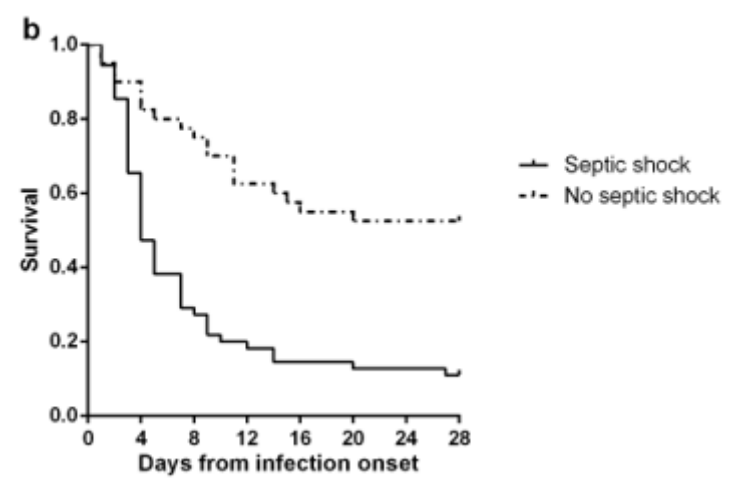

\section{Figure 1}

a. Kaplan-Meier curves for 28-day survival of BSIs due to MDR-A. baumannii, MDR-K. pneumoniae, MDR-P. aeruginosa and MDR-E. coli $(P<0.001)$. b. Kaplan-Meier curves for 28-day survival of MDR-A. baumannii BSIs causing septic shock $(P<0.001)$. c. Kaplan-Meier curves for 28-day survival of MDR-A. baumannii BSIs with previous steroid treatment $(P=0.009)$. 